\title{
Everolimus treatment of abdominal lymphangioleiomyoma in five women with sporadic lymphangioleiomyomatosis
}

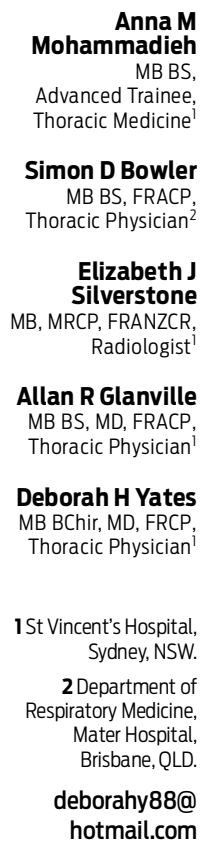

MJA 2013; 199: 121-123 doi: $10.5694 / \mathrm{mjal} 2.11567$

\section{L}

ymphangioleiomyomatosis (LAM) is a rare genetic disease affecting women of childbearing age. It may occur either as sporadic LAM (sLAM), or in association with tuberous sclerosis complex (TSC) (TSC-LAM). ${ }^{1}$ Although LAM is classically characterised by progressive, cystic destruction of the lung parenchyma, it also has extrapulmonary manifestations including chylous collections (in the abdomen and pleura), lymphadenopathy, benign tumours of the kidney (angiomyolipomas [AMLs]), and abdominopelvic cystic masses (lymphangioleiomyomas). ${ }^{1-4}$

In LAM, abnormal cells of smooth muscle lineage infiltrate the lungs and lymphatic system, and circulate through the blood. ${ }^{2}$ This has resulted in the characterisation of LAM as a benign metastatic tumour by some researchers. Accumulation of these cells in the lymphatic ducts results in obstruction and consequently chylous ascites and pleural effusions, and may also underlie the formation of lymphangioleiomyomas. The origin of the LAM cells is unknown. Predicting a prognosis for patients is difficult, but a 10-year survival from time of diagnosis has been estimated at about $80 \%-90 \%{ }^{5}$

The genetic mutation in women with LAM lies in one of two functionally related genes: the TSC1 gene (coding for hamartin on chromosome 9q34) or the TSC2 gene (coding for tuberin on chromosome 16p13). A mutation on the TSC2 gene is more common in SLAM. ${ }^{1,3}$ Loss of function of the hamartin-tuberin complex leads to inappropriate downstream constitutive activation of mammalian target of rapamycin (mTOR), a key regulatory protein in cell proliferation and lymphangiogenesis. ${ }^{1,2}$ Accordingly, there has been much recent interest in MTOR inhibitors as potential therapeutic agents in TSC and LAM.

One recent randomised controlled trial has confirmed that the mTOR

\begin{abstract}
Ahstract
Objective: Lymphangioleiomyomatosis (LAM) is a rare systemic disease of young women arising from mutations in the tuberous sclerosis complex (TSC) genes, TSC1 or TSC2. This disrupts the mammalian target of rapamycin (mTOR) pathway, affecting cellular proliferation and growth. MTOR inhibitors are a promising novel therapy in LAM. The mTOR inhibitor sirolimus is reported to produce resolution of lymphatic abnormalities in LAM, but the efficiacy of the mTOR inhibitor everolimus has not been assessed. We aimed to examine the efficacy of everolimus on lymphatic abnormalities in LAM.
\end{abstract}

Design, setting and participants: Open-label treatment of five patients with sporadic LAM (SLAM) and abdominopelvic and lung involvement at the outpatient LAM clinic of a tertiary city teaching hospital. Clinical data were collected during treatment of the women and included regular clinical reviews, everolimus levels, lung function and computed tomography assessment before and after 6 months of everolimus treatment.

Main outcome measures: Symptoms and level of resolution of lymphangioleiomyomas.

Results: All five women experienced significant shrinkage or complete resolution of the lymphangioleiomyomas during treatment. In one woman, cessation of everolimus resulted in recurrence of symptoms. Adverse events were compatible with the known side-effect profile of everolimus, but overall the drug was well tolerated.

Conclusions: This is the first report to suggest that everolimus has efficacy in the treatment of lymphangioleiomyoma and chylous ascites in SLAM.

inhibitor sirolimus is effective in stabilising decline in lung function in LAM. ${ }^{3}$ Sirolimus has also been associated with shrinkage of lymphangioleiomyomas and chylous effusions, in case reports ${ }^{6,7}$ and in one longitudinal series, ${ }^{8}$ as well as with shrinkage of renal AMLs. ${ }^{9,10}$ Temsirolimus has been linked to shrinkage of abdominal tumours in a single case report. ${ }^{11}$ The mTOR inhibitor everolimus has been associated with reductions in the size of giant cell astrocytomas and seizure frequency in patients with $\mathrm{TSC}_{1}^{12}$ and has recently been accepted by the United States Food and Drug Administration (FDA) for treatment of renal AMLs in TSC. ${ }^{13}$ Everolimus has not been reported in the treatment of lymphangioleiomyomas or chylous ascites.

We describe a series of five women with SLAM, all of whom had clinically significant lymphangioleiomyomas. All five women had a dramatic shrinkage and, in some cases, resolution of their tumours during therapy with everolimus.

\section{Methods}

\section{Patients}

Five women (mean age, 35.2 years) with clinically significant abdominal lymphangioleiomyoma, with or without chylous ascites, were treated with everolimus at St Vincent's Hospital, Sydney, where a LAM clinic is established. The two women treated at the LAM clinic were prospectively studied according to a standardised protocol, while the three women seen as private patients are reported retrospectively. All five women had a histopathologically confirmed diagnosis of SLAM, according to European Respiratory Society guideline criteria. ${ }^{2}$ All women gave written, informed consent to publication of this case series. Treatment of the women at the LAM clinic was approved by the St Vincent's Hospital Drug Committee, and the everolimus therapy was funded by the hospital at an estimated cost of about $\$ 10000$ per patient per year.

Clinical features of the participating women are shown in Box 1. All women 
had lung involvement with varying severity. Three of the women had been treated for abdominal LAM before everolimus therapy, without success.

\section{Everolimus treatment}

Patients were treated with twice daily everolimus at a starting dose of $0.5 \mathrm{mg}$ twice daily or $0.75 \mathrm{mg}$ twice daily. Serum everolimus levels were monitored and the dose was titrated to maintain target serum concentrations of $2-4 \mu \mathrm{g} / \mathrm{L}$, which is the low end of the therapeutic range used for lung transplantation $(3-8 \mu \mathrm{g} / \mathrm{L})$. Data collected included lung function at baseline and at 6 months, serial abdominopelvic imaging and regular blood monitoring, including liver function tests and blood lipid levels. Patients were seen initially after the first 2 weeks, then at 1 month, 3 months and 6 months unless side effects determined more frequent review. At each review, patients were monitored for adverse effects by clinical examination and blood tests, including everolimus levels. Lung function testing was repeated at 2 months and 6 months, and computed tomography scans were repeated at 6 months. All patients currently continue with everolimus therapy.

\section{Results}

\section{Abdominal lymphangioleiomyomas and chylous ascites}

All five patients had significant abdominal lymphangioleiomyomas at baseline, the largest of these measuring $17.5 \mathrm{~cm}$ at its maximum dimension (Box 1 and Box 2). Two patients had chylous ascites at baseline. Six months after initiation of everolimus, four of the five participants had experienced significant shrinkage or complete resolution of their lymphangioleiomyomas, and of the chylous ascites (where applicable). One woman experienced clinical resolution of her abdominal pain and distension but did not have confirmatory follow-up imaging due to financial constraints. In one woman, temporary cessation of everolimus resulted in recurrence of abdominal distension, requiring reinstitution of therapy.

\section{Lung function}

Lung function was abnormal in all five patients at presentation. There was no significant change in any lung function parameter over the treatment period, whereas a decline would possibly have been expected. However, no patient had severe lung involvement, one had a chylothorax at presentation and the overall number of patients was very small. Interpretation of these results is difficult because of the small number of patients. In the patient with chylothorax, complete resolution occurred.

\section{Adverse events}

The commonest adverse events were buccal ulcers and respiratory tract infections, which are consistent with the known side effects of everolimus. The most severe adverse event that ocurred during treatment was in Patient 1, who developed appendicitis which required appendicectomy. All women continued to menstruate throughout treatment, but Patient 5 had a new onset of heavy vaginal bleeding, which was investigated urgently in view of the fact that she was perimenopausal and everolimus treatment has been previously described as being associated with amenorrhoea. The patient was diagnosed with Stage 1 endometrial carcinoma, and was successfully treated with hysterectomy. Adverse events experienced by the participants are summarised in Box 1.

\section{Discussion}

Although LAM frequently presents with respiratory symptoms, abdominal involvement occurs in up to $70 \%$ of cases, ${ }^{14}$ with abdominal lymphangioleiomyomas in $16 \%$ of cases. ${ }^{2}$ Women may present with abdominal pain and swelling, and refractory chylous ascites, or with non-specific signs such as infertility or perimenstrual abdominal discomfort. ${ }^{4}$ Treatment is generally unsatisfactory, with medical therapies ineffective, and repeated abdominocentesis resulting in fluid reaccumulation, protein loss and potential infection.

The use of mTOR therapy in LAM is a targeted approach to an abnor-

\begin{tabular}{|c|c|c|c|c|c|}
\hline Characteristic & Patient 1 & Patient 2 & Patient 3 & Patient 4 & Patient 5 \\
\hline Age (years) & 25 & 36 & 29 & 33 & 53 \\
\hline Smoking history & Never smoked & $\begin{array}{l}10 \text { pack-years, } \\
\text { quit at } 36 \text { years }\end{array}$ & Never smoked & Never smoked & $\begin{array}{l}\text { "Social" smoker } \\
\text { (<1 pack-year) }\end{array}$ \\
\hline Comorbidities & $\begin{array}{l}\text { Uterine fibroids, endometrial polyp, } \\
\text { bilateral breast fibroadenomata, } \\
\text { phyllodes tumour } \\
\text { (right breast) }\end{array}$ & Childhood asthma & $\begin{array}{l}\text { Polycystic ovary } \\
\text { syndrome, depression }\end{array}$ & None & $\begin{array}{l}\text { Childhood asthma, } \\
\text { uterine fibroids }\end{array}$ \\
\hline Presentation & Recurrent bilateral pneumothoraces & $\begin{array}{l}\text { Abdominal pain and } \\
\text { distension }\end{array}$ & $\begin{array}{l}\text { Incidental abdominal } \\
\text { mass }\end{array}$ & $\begin{array}{l}\text { Infertility, abdominal } \\
\text { distension }\end{array}$ & $\begin{array}{l}\text { Recurrent bilateral } \\
\text { pneumothoraces }\end{array}$ \\
\hline $\begin{array}{l}\text { Lymphangioleiomyoma } \\
\text { size at presentation* }\end{array}$ & $8.3 \mathrm{~cm} \times 4.3 \mathrm{~cm} \times 17.5 \mathrm{~cm}$ & $\begin{array}{l}3 \mathrm{~cm} \times 1 \mathrm{~cm} \\
\text { (coronal view) }\end{array}$ & $\begin{array}{l}9 \mathrm{~cm} \times 3.5 \mathrm{~cm} \\
\text { (sagittal view) }\end{array}$ & $\begin{array}{l}5.1 \mathrm{~cm} \times 2.3 \mathrm{~cm} \\
\text { (axial view) }\end{array}$ & $\begin{array}{l}3.1 \mathrm{~cm} \times 10 \mathrm{~cm} \\
\text { (axial view) }\end{array}$ \\
\hline $\begin{array}{l}\text { Lymphangioleiomyoma } \\
\text { size after } 6 \text { months' } \\
\text { everolimus treatment* }\end{array}$ & Undetectable & $\begin{array}{l}\text { Virtually } \\
\text { undetectable }\end{array}$ & Clinical resolution & $\begin{array}{l}3.7 \mathrm{~cm} \times 1.8 \mathrm{~cm} \\
\text { (axial view) }\end{array}$ & Undetectable \\
\hline $\begin{array}{l}\text { Treatment of abdominal } \\
\text { LAM prior to everolimus }\end{array}$ & None & $\begin{array}{l}\text { Radiotherapy, } \\
\text { doxycycline }\end{array}$ & $\begin{array}{l}\text { Surgical excision, } \\
\text { abdomino-centesis }\end{array}$ & Doxycycline & None \\
\hline $\begin{array}{l}\text { Adverse events while } \\
\text { being treated }\end{array}$ & $\begin{array}{l}\text { URTI, influenza } A \text {, } \\
\text { ear pain, acute appendicitis }\end{array}$ & $\begin{array}{l}\text { Nausea, upper } \\
\text { respiratory tract } \\
\text { infection }\end{array}$ & Acne exacerbation & $\begin{array}{l}\text { Buccal ulcer, sciatica, } \\
\text { transaminitis, } \\
\text { lymphopenia, myalgia }\end{array}$ & $\begin{array}{l}\text { Buccal ulcers, diarrhoea, } \\
\text { vaginal bleeding } \\
\text { diagnosed as endometrial } \\
\text { carcinoma }\end{array}$ \\
\hline
\end{tabular}

$\mathrm{CT}$ = computed tomography. $\mathrm{LAM}=$ lymphangioleiomyomatosis. URTI = upper respiratory tract infection. * Measured using CT 
2 Abdominal computed tomography scans of Patient 1 showing $(A)$ a baseline coronal view with a large multilobulated mass (measuring $8.3 \mathrm{~cm} \times 4.3 \mathrm{~cm}$ axially and $17.5 \mathrm{~cm}$ longitudinally) in the para-aortic region (arrow), consistent with lymphangioleiomyoma; and (B) marked regression of the mass after 9 months of everolimus therapy

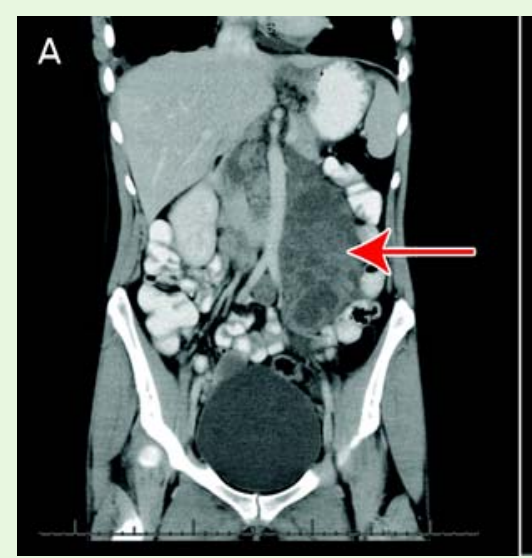

mality arising from a genetic mutation affecting multiple systems. The 2011 MILES trial showed that treatment with sirolimus in LAM was associated with a slower decline in lung function, improvement in quality of life and shrinkage of renal AMLs, but abdominal LAM was not the focus of that trial. ${ }^{3}$ To date, single-case reports and one observational series have documented regression of abdominal lymphangioleiomyomas with sirolimus or temsirolimus treatment, ${ }^{6-9,11}$ but there are no reports on everolimus. Our case series suggests that the efficacy of mTOR inhibitors extends to everolimus, and that this has good effect on abdominal LAM, which has been very difficult to treat in the past. Previous studies have shown that mTOR inhibitor treatment needs to be continued in TSC, but longitudinal data in LAM are limited. ${ }^{3,7}$ This is the first study to report everolimus treatment for LAM for several years, with all five women continuing on everolimus therapy. This is significant because the efficacy of mTOR inhibitors appears to rely on sustained therapy. 3,11

Everolimus is a derivative of sirolimus and has a very similar sideeffect profile. It has a shorter elimina-
B

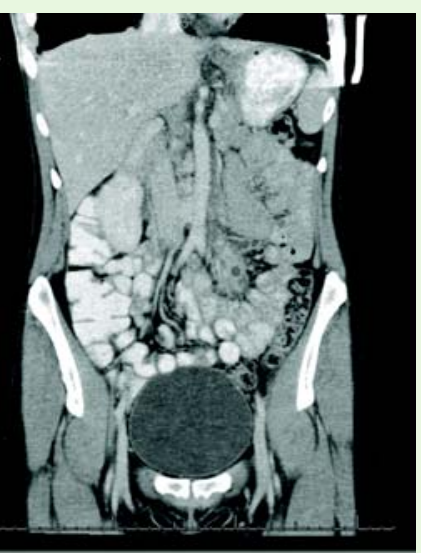

Received 22 Oct 2012, accepted 13 Mar 2013.

1 Chorianopoulos D, Stratakos G. Lymphangioleiomyomatosis and tuberous sclerosis complex. Lung 2008; 186: 197-207.

2 Johnson SR, Cordier JF, Lazor R, et al; Review Panel of the ERS LAM Task Force. European Respiratory Society guidelines for the diagnosis and management of

lymphangioleiomyomatosis. Eur Respir J 2010; 35: 14-26.

3 McCormack FX, Inoue Y, Moss J, et al; National Institutes of Health Rare Lung Diseases Consortium; MILES Trial Group. Efficacy and safety of sirolimus in

lymphangioleiomyomatosis. N Engl J Med 2011; 364: 1595-1606.

4 Sandrini A, Silverstone E, Yates DH. Menstrual cycle variation of retroperitoneal lymphangioleiomyomas in abdominal lymphangioleiomyomatosis. Intern Med J 2011; 41 832-835.

5 Johnson SR, Whale Cl, Hubbard RB, et al. Survival and disease progression in UK patients with lymphangioleiomyomatosis. Thorax 2004; 59 800-803.

tion half-life (about 30 hours) and greater relative bioavailability, compared with sirolimus. ${ }^{15}$ We used a lower dose of everolimus than the dose of sirolimus that was used in the MILES trial. The everolimus dose we used was consistent with the lower range of doses used in lung transplantation in our centre, with the aim of producing fewer side effects. Overall, everolimus was well tolerated and side effects, although significant, were within its described profile.

In summary, all women with sLAM showed a good response to treatment, with disappearance or shrinkage of abdominal lymphangioleiomyomas in four of five of cases, and clinical resolution of the lymphangioleiomyoma in the fifth. Abdominal symptoms resolved. Cessation of the therapy in one patient resulted in recurrence of ascites, and reinstitution of treatment resulted in resolution again. This is similar to the MILES trial, in which continued treatment was required. ${ }^{3}$ We suggest that everolimus treatment may be an effective long-term therapy for lymphangioleiomyomas and chylous ascites, which requires further evaluation in an appropriately designed controlled trial.

Competing interests: No relevant disclosures.
6 Taillé C, Debray MP, Crestani B. Sirolimus treatment for pulmonary lymphangiol687-688.

7 Morton JM, McLean C, Booth SS, et al. Regression of pulmonary lymphangioleiomyomatosis (PLAM)-associated retroperitoneal angiomyolipoma post-lung transplantation with rapaymcin treatment. J Heart Lung Transplant 2008; 27: 462-465.

8 Taveira-DaSilva AM, Hathaway 0, Stylianou M, Moss J. Changes in lung function and leiomyomatosis treated with sirolimus. Ann Intern Med 2011; 154: 797-805.

9 Herry I, Neukirch C, Debray MP, et al. Dramatic effect of sirolimus on renal angiomyolipomas in a patient with tuberous sclerosis complex. Eur J Intern Med 2007; 18: 76-77.

10 Bissler JJ, McCormack FX, Young LR, et al. Sirolimus for angiomyolipoma in tuberous NEngl J Med 2008; 358: 140-151.

11 Piha-Paul SA, Hong DS, Kurzrock R. Response of lymphangioleiomyomatosis to a mammalian target of rapamycin inhibitor (temsirolimus)based treatment. J Clin Oncol 2011; 29: e333-e335.

12 Krueger DA, Care MM, Holland K, et al. Everolimus for subependymal giant-cell astrocytomas in tuberous sclerosis. N Engl J Med 2010; 363: 1801-1811.

13 Franz DN. Everolimus: an mTOR inhibitor for the treatment of tuberous sclerosis. Expert Rev Anticancer Ther 2011; 11: 1181-1192.

14 Avila NA, Kelly JA, Chu SC, et al. Lymphangioleiomyomatosis: abdominopelvic CT and US findings. Radiology 2000; 216: 147-153.

15 Formica RN Jr, Lorber KM, Friedman AL, et al. The evolving experience using everolimus in clinical transplantation. Transplant Proc 2004; 36 (2 Suppl): 495S-499S. eiomyomatosis. Ann Intern Med 2007; 146: chylous effusions in patients with lymphangiosclerosis complex or lymphangioleiomyomatosis. 